\title{
THE WEAR CONDITION OF SPUR GEARBOX UNDER VARIABLE LOADS USING WEAR DEBRIS ANALYSIS TECHNIQUE - AN INVESTIGATION
}

\author{
A. S. KUSHWAH \& R. B. SHARMA \\ Department of Automobile Engineering, RJIT, Boarder Security Force Academy, \\ Tekanpur, Gwalior, Madhya Pradesh, India
}

\begin{abstract}
The wear is a very common phenomenon during the meshing of the gears. The development and progression of the wear in gears may create catastrophic failures. In this study, the progression of wear condition in the gear has been predicted with on-line wear debris monitoring from lubricating oil together with visual inspections. The experimental set up has been designed and the experiments were conducted with spur gears under varying load condition. The effect of different load conditions on the progression of wear condition in the gear has been presented. The results demonstrate that the concentration and weight of particles in lubrication oil, and the measured area of wear exist on gear surface during wear progression correlate well with the severity of wear condition of gear acquired from the visual inspection.

KEYWORDS: Gears, Wear, On-Line Particle Monitoring, Wear Debris Analysis \& Load
\end{abstract}

Received: Jun 18, 2017; Accepted: Jul 08, 2017; Published: Jul 17, 2017; Paper Id.: IJAuERDAUG20171

\section{INTRODUCTION}

A gear is a rotating machine part, having cutting teeth, which mesh with another toothed part for transmitting motion. Gear wear is one of the most common factors resulting in failures of power transmission system [1].There are mainly three types of wear; fatigue wear, adhesive wear, abrasive wear. A combined form of these three wears may occur in the service life of gear box due to changing of lubricating states [2]. Gear wear has not been explained completely due to complexity like time dependent, system dependent and physical attachment $[3]$.

Macroscopic pitting is the main factor for failure of gear flank caused by periodic contact stresses. This may cause cracks initiating from surfaces that finally leads to detachment of a macropit. It generally occurs at dedendum of tooth flank, where both sliding velocity and stress are in a great degree. Formation of pitting is generally detected by visual inspections and by photography of tooth flank portion. Visual inspection is a time consuming process and not provides continuous information of pitting.it provides information only at a single stage. Inspection of pitting would be improved if progressive information of pitting found [4].

It is difficult to measure wear of gear pair without changing the contacts and lubrication conditions. There are some indirect methods to measure wear symptoms like oil particle contamination, temperature, acoustic, vibrations. Ferrography and spectrometric methods are the main tools measuring degree of wear. Offline methods like visual inspection, photography are laborious hence provides too late information. In online particle method, the pit and other contaminates in oil is detected continuously with specific sensors at gear box outlet [5-6].

Spectrographic oil analysis (SOA) is effective for wear debris analysis with size under 10 $\mu \mathrm{m}$ [7].Off-line 
ferrography covers size range of debris under $100 \mu \mathrm{m}$ [8]. Since automation for analysis of debris contamination is in progression therefore these old methods for testing are being obsolete.

Salgueiro et al. [9] applied an electromagnetic metallic particle sensor, that counts ferrous particles of size ranges from 40 to $300 \mu \mathrm{m}$, to monitor the pitting test in single-stage gear box and concluded that the amount of wear particles followed the trend of load level. Feng et al. [10] predicted wear of a spur gearbox and observed early-warning signs of abnormal wear behavior related to pitting and scug by employing an on-line visual ferrograph with an index of particle coverage area to characterize wear debris concentration. Martin [11] studied oil contaminants usually found from machines and engines by using digital imaging and digital shape recognition and concluded that it was possible to separate reliably real wear particles from other contaminants like bubbles and drops. This gives also the possibility to make form and particle size analysis for wear particles. Iwai et al. [12] determined wear quantity of against each other rubbing components with on-line particle monitoring based on number of particles and their sizes. The used method correlated well with the measured values of mass loss of the specimen. However, lubricating oil can contain some other contaminants which decrease the accuracy of real wear particle counting. Sugimura et al. [13] used wear image analysis in wear debris analysis to characterize different progress of wear in gears.

For real time wear monitoring, on-line visual ferrograph (OLVF) is developed based on magnetic deposition and image analysis[14-16]. A new experimental method for assessing anti-wear properties of lube oil in different wear stages has been developed[17].OLVF has been implemented on engine bench experiments to find out abnormal wear[17-19]. Wear debris monitoring can detect gear surface pitting faster than vibration analysis [20].

\section{EXPERIMENTAL INVESTIGATION}

\section{Experimental Setup}

Figure 1 shows the experimental setup.Main components of this experimental setup are following-:

Motor

\begin{tabular}{|c|c|c|c|}
\hline \multirow[t]{5}{*}{ Specifications-: } & Type & - & $\mathrm{AC}$ \\
\hline & Phase & - & 1 \\
\hline & Voltage Rating & - & $220 \mathrm{~V}$ \\
\hline & Current Rating & - & 2 Amps \\
\hline & RPM & - & 1440 \\
\hline
\end{tabular}

\section{Flexible Coupling}

Specifications-:

Type
Material

Specifications-:

\section{Loading Arrangement}

- 6 fingered star

Teflon

$\begin{array}{llll}\text { Specifications-: } & \text { Type } & - & \text { Belt } \\ & \text { Material } & - & \text { Rubber }\end{array}$


The Wear Condition of Spur Gearbox under Variable Loads using Wear Debris Analysis Technique - An Investigation

\section{Gear Box}

Table 1: Details of Test Gears

\begin{tabular}{|l|c|c|}
\hline \multicolumn{1}{|c|}{ Parameter } & Pinion & Wheel \\
\hline Number of teeth & 14 & 21 \\
\hline Module $(\mathrm{mm})$ & 6 & \\
\hline Center distance $(\mathrm{mm})$ & 115 & \\
\hline Pressure angle $(\mathrm{deg})$ & 15 & \\
\hline Addendum modification & +0.282 & +0.0707 \\
\hline Face width $(\mathrm{mm})$ & 6 & \\
\hline Roughness Ra $(\mu \mathrm{m})$ & $2-3$ & \\
\hline Hardness $(\mathrm{HRC})$ & $40-45$ & \\
\hline Material & $\mathrm{MS}$ & \\
\hline Volume of oil $(\mathrm{L})$ & $1 / 2$ & \\
\hline
\end{tabular}

\section{Gear Oil}

Table 2: The Details of Gears Oil

\begin{tabular}{|l|c|}
\hline \multicolumn{1}{|c|}{ Parameters } & Rating \\
\hline sSAE grade & 90 \\
\hline Kinematic Viscosity cSt $@ 100^{\circ} \mathrm{C}$ & $16-18$ \\
\hline Viscosity Index, Min. & 90 \\
\hline Flash point $(\mathrm{COC}),{ }^{\circ} \mathrm{C} \mathrm{Min.}$ & 180 \\
\hline Pour point, ${ }^{\circ} \mathrm{C} \mathrm{Max.}$ & $(-) 9$ \\
\hline
\end{tabular}

Base

$\begin{array}{llll}\text { Specifications-: } & \text { Platform Material } & - & \text { Wood } \\ & \text { Stand Material } & - & \text { Iron }\end{array}$

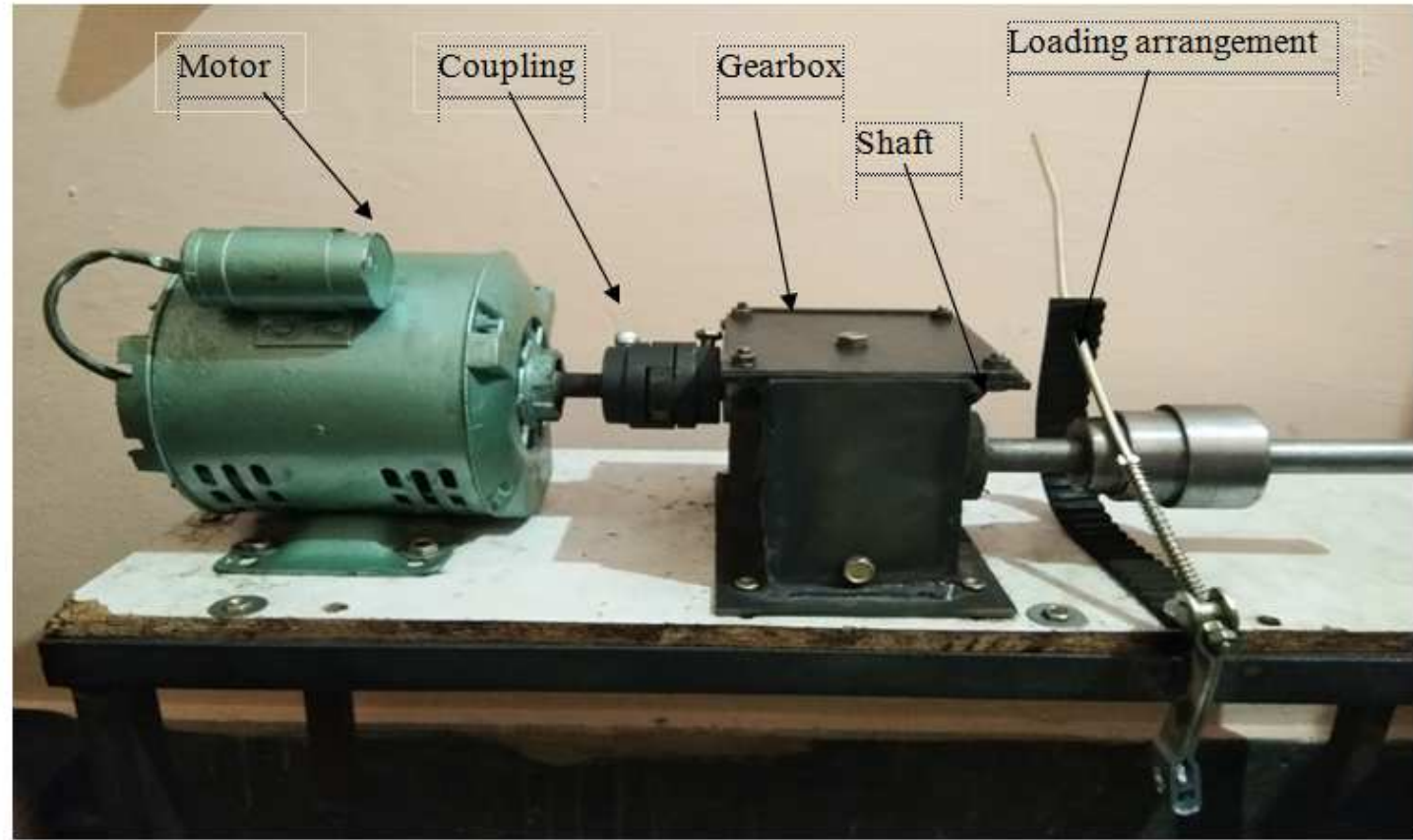

Figure 1: Experimental Setup 


\section{Test Procedure}

At first, the gear box is cleaned with solvent then the gear oil is circulated inside the gear box and electrical supply provided to the motor. Running of motor is maintained for two hours for maintaining oil temperature. At a speed of $1440 \mathrm{rpm}$, motor will run for around 20 hours and increasing the load in 4 stages from $10 \mathrm{~N}$ to $40 \mathrm{~N}$. Tests are started from $10 \mathrm{~N}$, At this load, reading are carried out for different time periods ranging from 20 hours to 80 Hours. then inspection documented by visual inspections by measuring two things, one is area of wear on gear and second is weight of debris taken by filtering oil suspended from gear box for all time intervals. By measuring these two things, generate a graph between cumulative particles found during wear and hours for a load of 10N.The working principle for wear debris analysis is shown in Figure 2. Finally, all measurement is taken for load $10 \mathrm{~N}$, which is provided by loading arrangement $\&$ graph generated. This same working principle we follow for $20 \mathrm{~N}, 30 \mathrm{~N} \& 40 \mathrm{~N}$ and these two things are measured. Therefore, four graphs are generated between cumulative particles and hours for different load conditions. At the same time, we also detect are of wear on gear at different time intervals for the same loads. So, again four graphs generated between Area of wear on gears and hours for different load conditions. Then a comparative study is carried out between graphs for area of wear and cumulative particles for different loads.

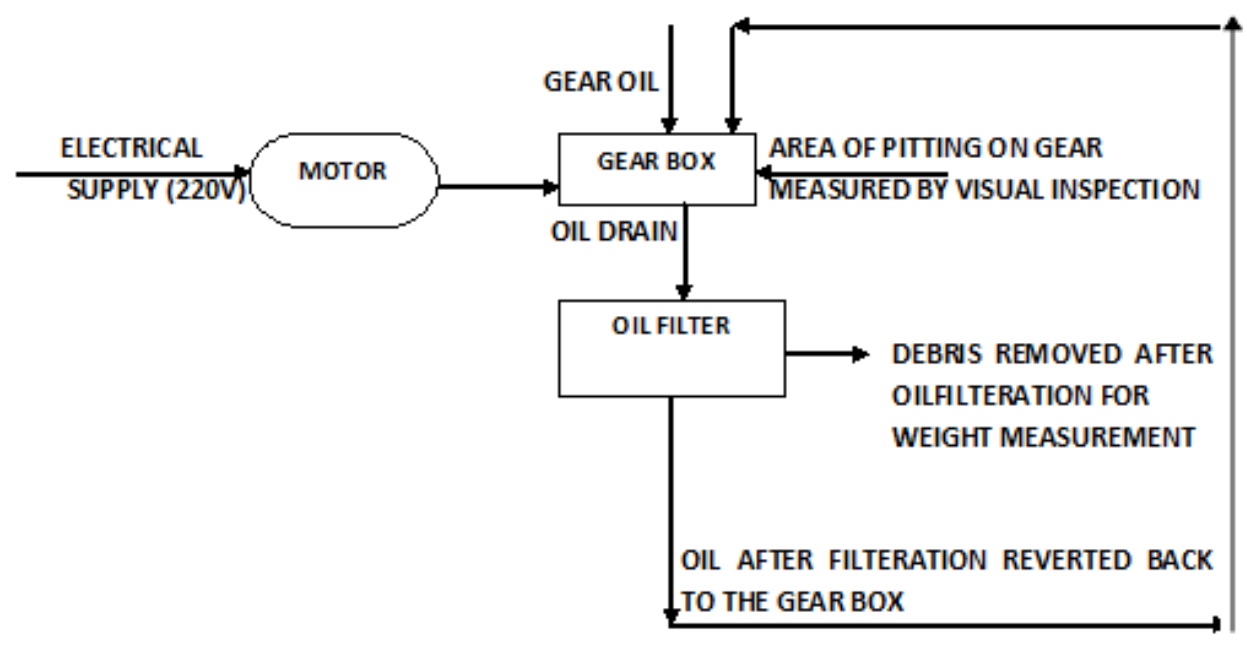

Figure 2: Working Principle for Wear Debris Analysis

\section{RESULTS \& DISCUSSIONS}

\section{Measurement of Weight of Debris under Different Load Conditions}

This analysis has been taken into account for measuring the weight of debris under variable loads. The results of continuous inspection of oil outlet in the range from 20 to 80 hours for various loads are recorded. For a load of $10 \mathrm{~N}$, weight of debris found almost negligible up to 20hours, after that a high rate of progressive wear particles were found up to 40 hours; then again there is a slow progression for up to 60hours, then again a high progression for upto 80hours. Now, for a load of $20 \mathrm{~N}$, a high rate of progression was found initially as comparative to $10 \mathrm{~N}$, but not in a great manner, after that progression of wear continuously increased as compare to previous curve. This same procedure was adopted for $30 \mathrm{~N} \&$ 40 N. For these loads, the wear found progressive as compared to previous curve. Hence, as the load increases, the progression was found for weight of debris. But, a high rate of debris possibilities found for heavy load means, the weight of debris may be found more, under heavy load conditions within a short period of time. 

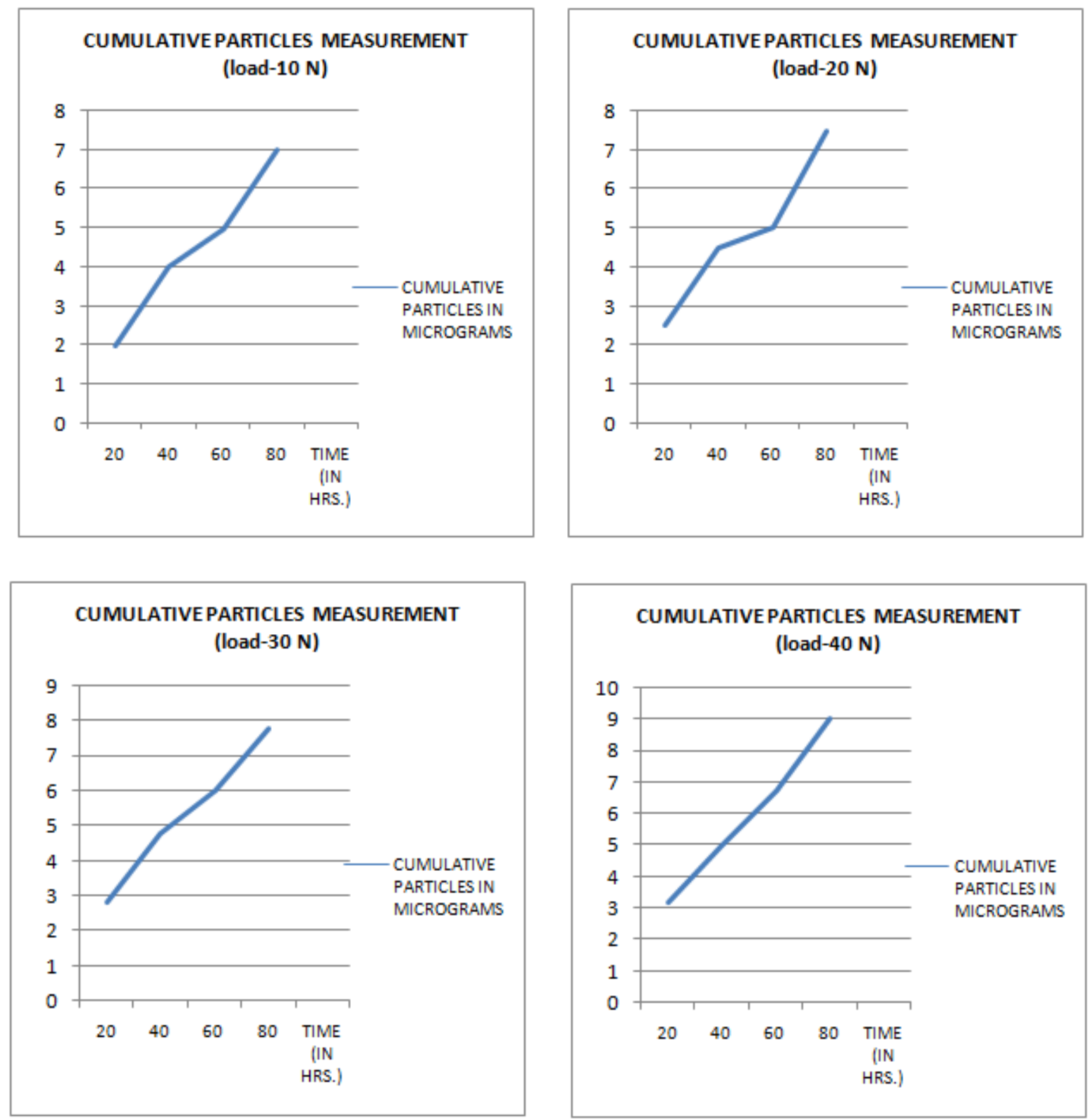

Figure 3: Cumulative Particles Measurement at Various Loads

\section{Measurement of Area of Wear on Gears at Various Loads}

This analysis has been taken into account for measuring the area of wear on gear for variable loads. The result of continuous inspection of oil outlet in the range from 20 to 80 hours for various loadstaken. For a load of 10N, a minor rate of wear was found on gear meshing point up to 20hours, after that a high rate of progressive wear found up to 40 hours, then again there was a slow progression for up to 60hours, and then again a high progression on gear for upto 80hours. Now, for a load of $20 \mathrm{~N}$, a high rate of area of wear was found initially as compared to $10 \mathrm{~N}$, but not in a great manner, after that progression of wear on gear continuously increased as compared to previous curve. This same procedure was adopted for $30 \mathrm{~N} \& 40 \mathrm{~N}$. For these loads, the wear was found progressive, as compared to previous curve. Hence, as the load increases, the area of wear on gear will be progressive. But, early wear possibilities found for heavy load means, high rate 
of wear may be found under heavy load, within a short period of time.
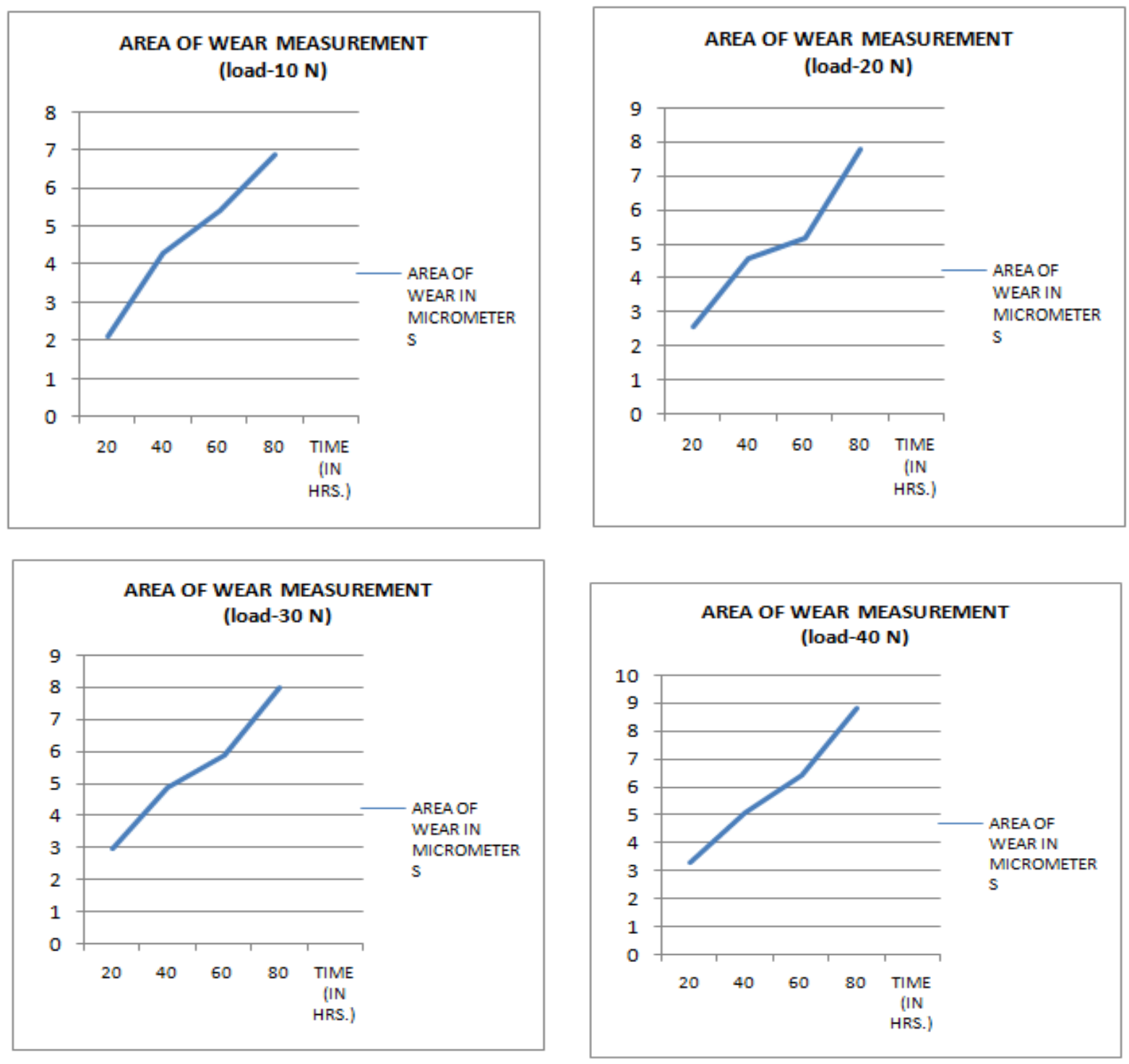

Figure 4: Area of Wear Measurement at Various Loads

\section{CONCLUSIONS}

The gear pitting progression has been detected by measuring area of pitting and weight of debris particles. This test was carried out on a Single speed spur gear box. This was done by visual inspections and particles quantified by weight measurement, after oil filtration for various loads. The main conclusions drawn are:

- As the load increases, the debris particles formation will be faster as compare to previous one.

- Area of pitting on gears will be progressive, as the load increases.

- After completion of experiment, one conclusion finds that the gear pitting progression correlates well with amount of debris, quantified for various loads. 
The Wear Condition of Spur Gearbox under Variable Loads using Wear Debris Analysis Technique - An Investigation

- $\quad$ Enhancement of major wear on gears is initiated by minor wear.

- Hence, it is feasible to predict wear condition of gears, by measuring weight of debris particles as well as the measured area of wear existing on the gear surface, during wear progression.

\section{REFERENCES}

1. Errichello R, Muller J. Gear box reliability collaborative gear box 1 failure analysis report, Report NREL/SR-5000-53062, Contract no. DE-AC36-08G028308, 2012.

2. Lester EA. Systematic analysis of gear failures, ASM International, Geauga country, 1985.

3. Xie YB. Three axioms in tribolgy, Tribology 21 (2001) 161-166.

4. Appearance of gear teeth- terminology of wear and failure. American Gear Manufactures Association. American National Standard, ANSI / AGMA 1010-F14.

5. Glaeser W. Wear debris classifications, (chapter in) Modern tribology handbook, two volume set (editor in chief). Boca Raton, London: Bharat Bhushan, CRC Press; 2000, [ISBN: 0-8493-8403-6].

6. Evans JS, Hunt T. Oil analysis handbook, $1^{\text {st }}$ edition. Oxford, UK: Coxmoor publishing company; 2004. p. 157, [ISBN: 1901892-05-01.

7. Vahoja P, Valimaki I, Roppola K, Kuokkanen T, Lahdelma S. Wear metal analysis of oils, Crit: Rev. Anal. Chem. 38 (2008) 67-83.

8. Roylance BJ. Ferrography- then and now, Tribolgy International 38 (10) (2005) 857-862.

9. Salgueiro J, Persin G, Hrovatin J, Juricic D, Vizintin J. On-line detection of incipient trend changes in lubricant parameters. IndLubr Tribology 2015;67/ 6:509-19.

10. Feng S, Fan B, Mao J, Xie J. Prediction on wear of a spur gearbox by on-line wear debris concentration monitoring. Wear 2015;336-337:1-8.

11. Martin P. Online-monitoring von Objekten (Partikel, Blasen, Tröpfchen) in Schmierölen von Motoren und Getrieben auf TestständenzurVerschleiß- und Funktionsüberwachung. Tribol und Schmier 2015;62/5:43-53.

12. Iwai Y, Honda T, Miyajima T, Yoshinaga S, Higashi M, Fuwa Y. Quantitative estimation of wear amounts by real time measurement of wear debris in lubricating oil. Tribology Int 2010;43:388-94.

13. Sugimura CJ, Takesue M, Yamamoto Y. Wear debris analysis for condition monitoring of gears. in: Dowson D., Taylor C.M., Childs T.H.C., Dalmaz G., Berthier Y., Flamand L., Georges J.-M. andLubrecht A.A., Editors. Tribology for Energy Conservation, In: Proceedings of the 24th leeds-lyon symposium on tribology, p. 431-442; 1998.

14. Wang JT. Theoretical and experimental study on on-line visualization ferrograph sensor, Xi'an Jiaotong University, Theory of lubrication and bearing institute, Shaanxi, China, 2006.

15. Wu TU, Mao JH, Wang JT, Wu JY, Xie YB. A new on-line visual ferrograph,Tribol. Trans. 52 (2009) 62-631.

16. Ding X. Study on deposition characteristics of wear particles of wear particles and wear monitoring method for on-line visual ferrograph sensors, Xi'an Jiaotong University, Theory of lubrication and bearing institute, Shaanxi, China, 2011.

17. Feng S, Che YT, Mao JH, Xie Y.B. Assessment of anti wear properties of lube oils using on-line visual ferrographmethod,Tribol.Trans. 5(2014) 336-344.

18. Zhang YL, Mao JH, Xie YB, Engine wear monitoring with OLVF, Tribol. Trans. 54 (2011) 201-207. 
19. Wu JY, Mi XY, Wu TH, Mao JH, Xie YB. A wavelet-analysis-based differential method for engine wear monitoring via online visual ferrograph, J. Eng. Tribol. 227(12) (2013) 1356-1366

20. Vizintin J. Tribolgy of mechanical systems: A guide to present and future technology- Expert systems in condition monitoring, ASME Press, New York 2004. 